\title{
AODV-F: A New on Demand Enhanced Distance Vector Routing in Wireless Network
}

\author{
Pushpender Sarao
}

\begin{abstract}
Routing process is the main role in wireless ad-hoc networks. It is a very tedious task to complete successfully in mobile ad-hoc networks. Nodes are frequently changing their positions in mobile ad-hoc networks. In such a challenging environment, there are more chances of packet loss. So many routing protocols have been proposed to recover this loss. In this work, we have proposed a new distance vector routing algorithm that is an enhancement of existing routing protocol in mobile ad-hoc networks. We consider node power, hop count, and maximum speed to decide the next hop during the routing process. Trust values have been calculated by applying the rule based system. This trust value will decide the next hop in the network. To evaluate our proposed algorithm, we have simulated this in a network simulator-2 environment. Normalized routing load, throughput, packet delivery fraction, and delay are considered as the performance metrics to evaluate the proposed work.

Keywords-pause time, trust route, triangular membership function, NRL, overall delay, fuzzy rules;
\end{abstract}

\section{INTRODUCTION}

Ad-hoc network is a temporary network, in which there is no central administration system which will control the entire network responsible for communication. Here, limited range is available for each node for making the communication process (Sending and receiving messages).

In MANET, each node acts as a router as well as host. Therefore, each node can send as well as forward message to its neighbor node.

If there is limited transmission range (available for each node in MANET), then there is not possibility to direct communication to that node (who is far away). For that condition, node will forward message to neighbor node and neighbor node again forward that message to next node; until message is not passed to the destination node. Walkie-Talkie set is an best example for MANET to understand it's working. MANET is suitable for communication, the location where infrastructure establishment is not easily possible. Military operations are mostly performed through MANET networks. In emergency conditions (i.e. earth-quack), mobile ad-hoc network is a best suitable to make possible the communication.

Topology used in MANET is dynamic i.e. not fixed; it is frequently changed scenario to scenario. Each node has a

Manuscript published on 30 September 2019

* Correspondence Author

Pushpender Sarao*, CSE, Hyderabad Institute of Technology and Management, Hyderabad, India. Email: drpushpendersarao@gmail.com

(C) The Authors. Published by Blue Eyes Intelligence Engineering and Sciences Publication (BEIESP). This is an open access article under the CC-BY-NC-ND license http://creativecommons.org/licenses/by-nc-nd/4.0/ battery power in MANET and maintaining the sufficient battery power for communication is a big challenge. Sufficient bandwidth is also a changing work in MANET. Mostly bandwidth is fluctuated time to time. If any node is not in the transmission range, in that condition, message will be forwarded indirectly i.e. through neighbor node. Nodes are movable in MANET and frequently change their position. Therefore link breakage events occurred and communication problem will be happened. In such a challenging scenario, establishing a link is a tedious task.

For performing the routing process in MANET, several routing algorithms and protocols have been established. Some protocols are proactive and reactive; while other are hybrid (i.e. mixing the features of reactive as well as proactive protocols). In pro-active routing protocol, possible routes are already stored on each node. In reactive routing protocols, routes are established as demand for route is there. Ad-hoc on demand distance vector (AODV) is one of the reactive routing protocols. Route discovery as well as route maintenance service is provided by AODV protocol. Route discovery consists of route request and route reply. After route discovery process, a best route is selected. Messages are broadcasting in AODV to send the message to the destination node. In AODV, only one metric (i.e. minimum hop count) is considered while route selection. But, only one metric is not sufficient for route establishment, other metrics like bandwidth, throughput, and battery power are also to be considered. Extension of AODV is proposed by so many researchers [1][2][10][11] in literature. In some related work, five metrics have been used while in other only 3 metrics have been considered to establish an appropriate route between source to destination.

In this paper, we have proposed a fuzzy based enhancement for AODV to improve the performance of MANET. A fuzzy inference system will calculate the trust value to choose a next hop in the route establishment.

Three input parameters named 'Node power', 'Hop count', 'Max Speed' have been considered to generate output as 'Trust Value'. A 'Mamdani' type fuzzy system has been applied to execute the input membership functions. This paper is organized into five sections. Section II summarizes the related works which have been already proposed by many researchers. A detailed implementation of proposed work has been elaborated in section III (in fuzzy environment as well as network simulation scenarios). Results and discussion part is visualized through section IV. Section V discussed the Conclusion and future work. 


\section{RELATED WORK}

Antonio M. Ortiz - F et al. proposed a fuzzy based routing decision approach which will use the distributed routing algorithm [3].

Two fuzzy input parameters (number of hops and battery level) were used to calculate the output as node suitability. For role assigning and parent selection purposes, network role-based routing intelligent algorithm has been used. Total twenty fuzzy rules have been designed with several linguistic variables (very low, low, medium, high, low adequate, adequate, perfect, not adequate). Performance evaluation was done through packet sent, energy consumption, network self-organization type, number of forwarding nodes. At the end of this paper, it was claimed that proposed algorithm is efficient as compared to NORA and NORIA routing schemes in wireless sensor networks.

A trust-based secure routing algorithm is proposed in [4] for MANET network. This work is the extension of existing routing protocol AODV. Trust value and throughput were considered as input parameters for fuzzy system for fuzzy system for getting encryption action required. Total eleven fuzzy rules were designed for rule based system for two inputs with respect to one output. Unreliable, marginally reliable, reliable, extremely reliable, negligible, low, medium, and high linguistic variables were used for trust value and throughput membership functions (trapezoidal membership function, triangular membership functions). It was declared that proposed TBSRPM algorithm performs better than AODV for making the complete data transmission route.

In[5], Xing Hu et al. proposed a geographic routing algorithm for wireless sensor network. Here, fuzzy logic-based geographic routing algorithm is proposed with three input parameters (distance,density of node, distribution degree of the nodes) and one output parameter(comprehensive assessment of candidate node). In this work, fuzzy process was completed through fuzzification, fuzzy reasoning, defuzzification to calculate the comprehensive assessment of candidate node. Total twenty seven fuzzy rules were designed with three linguistic variables for each input and output membership functions. The proposed GPSR algorithm has been compared with the existing FLGR (Fuzzy Logic-based Geographic Routing). Simulation work was carried out in MATLAB to evaluate the performance of proposed GPSR routing protocol with varying the number of nodes. Performance parameters were considered as: speed, number of nodes, number of hops, frequency of hello messages, and routing overhead ratio.it was claimed that GPSR is capable to avoid the routing void problem. GPSR have lower overhead and improved PDR.

In [6], Gholamreza Kakamanshadi et al. introduced an enhancement over IHR (Internal Homed Routing) in wireless sensor network. The cluster forming process was performed through a fuzzy logic process. Also a comparison work is carried out for DHR (Dual-Homed Fault tolerant Routing), IHR, and FIH routing protocol. The proposed fuzzy based protocol is based on energy saving scheme. Also several preliminaries have been discussed for the simulation work. Two input parameters (residual energy and distance to base station) and one output parameter (communication range) were used with triangular membership functions. Total nine fuzzy rules were designed for the proposed fuzzy based protocol. FND (First Node Dead) and HNA (Half of Nodes Alive) metrics were used to evaluate the performance of FIHR protocol. It was declared that proposed FIHR is more energy saving protocol during the route establishment.

Sangeetha Pushpan and Bhanumathi Velusamy illustrate the extended algorithm [[7] which is efficient in respect of cost and minimum time for packet transmission during routing process in wireless body area networks. Here, fuzzy based dynamic time allocation scheme have been applied. Three fuzzy membership functions (energy ratio, buffer ratio, and packet arrival rate) are used as input parameters. Link Cost Function for Next-Hop Selection and Minimum Cost Parent Selection Algorithms has been used for selecting a node with minimum link cost and for the best parent node. Total twenty seven fuzzy rules were designed with three linguistic variables (Low, Medium, and High). Performance evaluation work for the proposed algorithm was carried out with considering the following performance parameters: Packet delivery ratio, Average End-to-End Delay, Average energy consumption (in respect of different simulation times and different packet intervals).

\section{PROPOSED WORK}

In order to enhance the AODV's efficiency, the integration of fuzzy logic to decide the appropriate route selection is proposed through AODV-F algorithm (described in table with number of steps). Here, next route decision is made on the basis of route trust value that is calculated with the help of fuzzy based system. This fuzzy system takes three inputs (hop count, maximum speed, and node power) and generates one output as route trust value. Next route will be decided only on the basis of this trust value at the time of routing process in mobile ad-hoc network.

\section{Proposed Algorithm: AODV-F}

Step1:Internal Node get Route Request

Step2:Calculate Trust Value for Internal Node

Step3:Route Request is new=True/False

If false

\{

Value=True/False

Has improving stored neighbour Node Trust If True $\}^{\text {If False }}$ Table and Send Route Reply to Source Node

If True

\{

Set timer for new Route Request and create new

reverse Route table Entry

\}

Step4: Timer expired for specific Route Request $=$ True/False

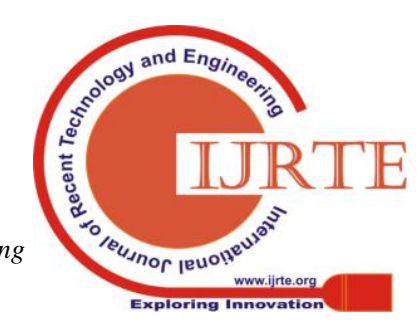


If False

\{

Go to step 1

$$
\}
$$

If True

\{

Check for destination Node=True/False

\{

If True

\{

Send Route Reply

\}

If False

\{

Broadcast Route Request having desired route Trust

Value

\section{\}}

\section{A. Mamdani-based implementation:}

To implement the proposed algorithm with the help of fuzzy system, we have applied 'Mamdani' type fuzzy rule system (figure 2) which will take inputs and produce one output as route trust value. To implement fuzzy based system, MATLAB 7[8] has been applied as a implementation platform. In our proposed fuzzy logic system, fuzzy system is processed in five phases(as shown in figure 1): 1) initialization phase, which covers decision for linguistic variables, generating the membership functions, rule base creation (2) fuzzification phase, which converts crisp values to fuzzy values (3) inference phase, which is used to evaluate the designed rules (4) aggregation, which combine the specific results per fuzzy rule (5) defuzzification, which replace output results into the non-fuzzy results.

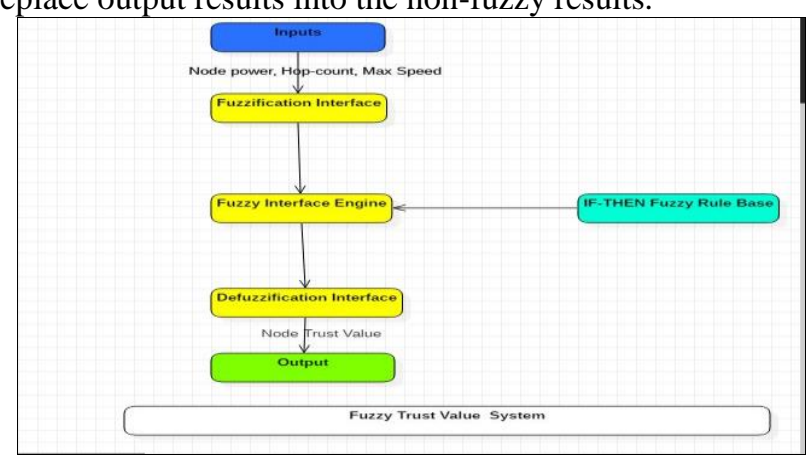

Figure 1: Fuzzy Trust Value System

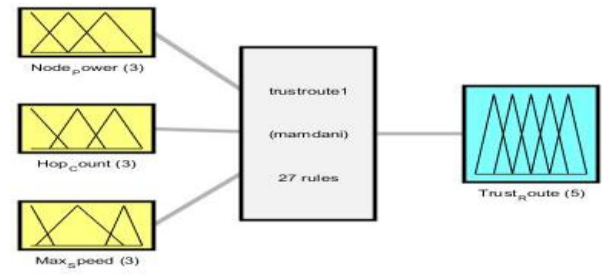

Figure 2: Mamdani system with 3 inputs, 1 outputs, 27 rules

The input parameters to be considered in the fuzzy system based experimental work are: hops count, node power, and maximum speed (see figure 3, 4, 5). The parameter 'Route Trust' is considered as output variable (figure 6) having five linguistic variables (very low, low, medium, high, and very high). For input parameters and output parameter, triangular membership function has been applied to produce an appropriate result. Fuzzy range, fuzzy sets details for input and output parameters are described in tables.

Table 1: fuzzy ranges for input and output parameters

\begin{tabular}{|l|l|l|}
\hline Fuzzy parameters & MIN & MAX \\
\hline Node power & 25 & 100 \\
\hline Hop count & 0 & 12 \\
\hline Max Speed & 0 & 24 \\
\hline Trust Route & 0 & 120 \\
\hline
\end{tabular}

Table 2: Fuzzy sets for input parameter 'Node Power'

\begin{tabular}{|l|l|}
\hline Fuzzy sets & $\begin{array}{l}\text { Node } \\
\text { Power }\end{array}$ \\
\hline Low & $\mathrm{L}(50,25,50)$ \\
\hline Medium & $(25,50,75)$ \\
\hline High & $(50,75,100)$ \\
\hline
\end{tabular}

Table 3: Fuzzy sets for input parameter 'Hop Count'

\begin{tabular}{|l|l|}
\hline Fuzzy sets & Hop Count \\
\hline Low & $\mathrm{L}(4,0,4)$ \\
\hline Medium & $(12,5,8)$ \\
\hline High & $(6,9,12)$ \\
\hline
\end{tabular}

Table 4: Fuzzy sets for input parameter 'Max Speed'

\begin{tabular}{|l|l|}
\hline Fuzzy sets & Max Speed \\
\hline Low & $\mathrm{L}(5,0,5)$ \\
\hline Medium & $(1,10,20)$ \\
\hline High & $(16,20,24)$ \\
\hline
\end{tabular}

Table 5: Fuzzy sets for output parameter 'Trust Route'

\begin{tabular}{|l|l|}
\hline Fuzzy sets & Trust Route \\
\hline V Low & $(0,20,40)$ \\
\hline Low & $(20,40,60)$ \\
\hline Medium & $(40,60,80)$ \\
\hline High & $(60,80,100)$ \\
\hline V High & $(20,100,120)$ \\
\hline
\end{tabular}




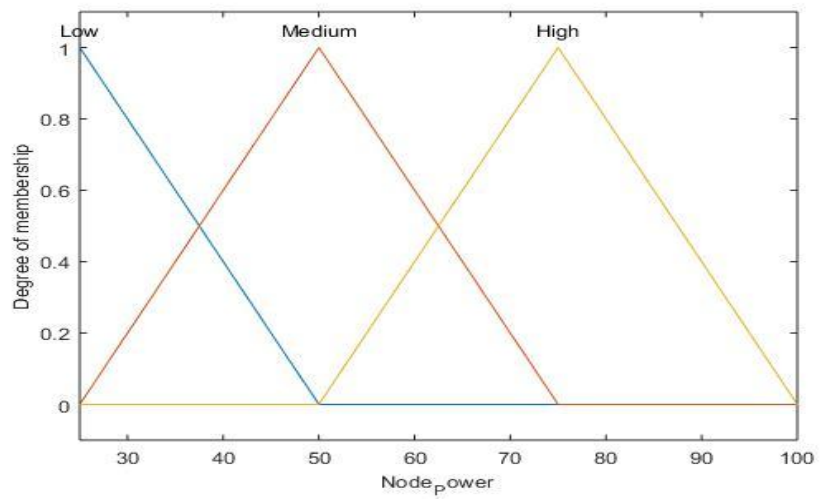

Figure 3: Input membership function 'Node Power'

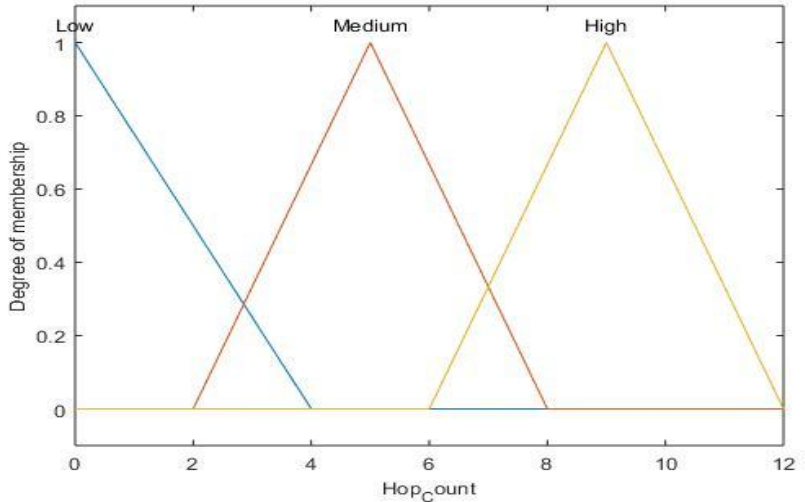

Figure 4: Input membership function 'Hop Count'

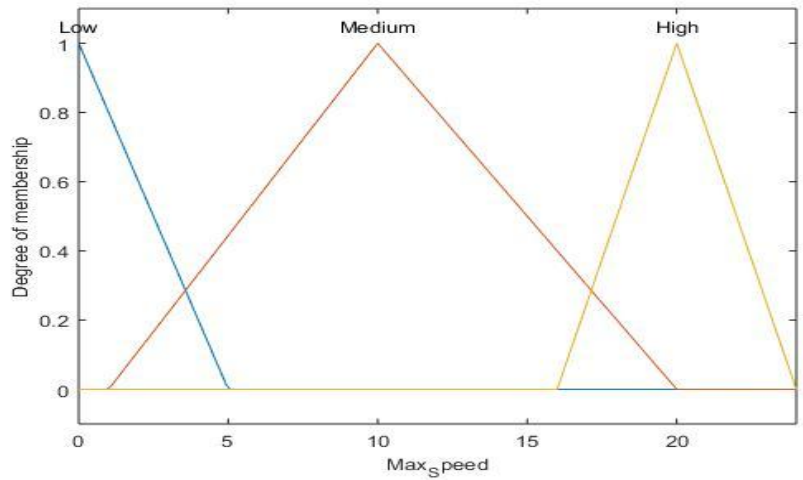

Figure 5: Input membership function 'Maximum Speed'

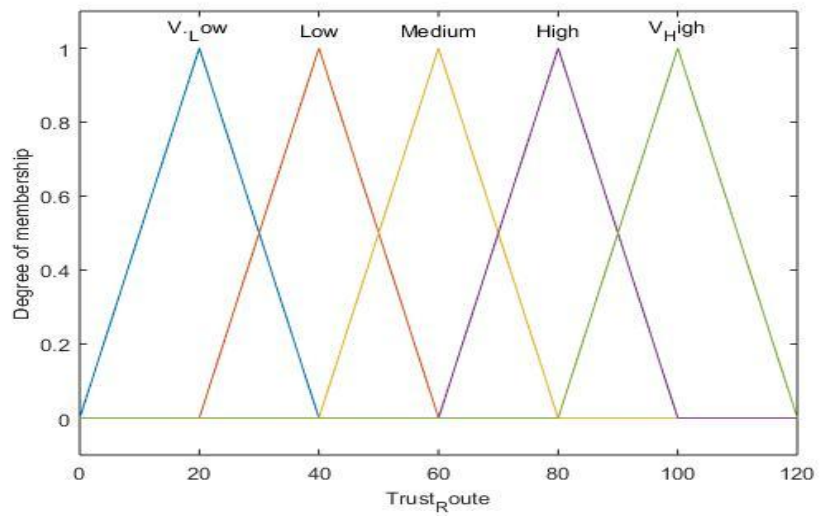

Figure 6: Output membership function 'Trust Route'

In our proposed fuzzy-based system, the fuzzy rules base having rules such as: If (Node_Power is Medium) and (Hop_Count is Low) and (Max_Speed is Low) then (Trust_Route is High). Here, since there are 3 fuzzy sets for Node power input, 3 fuzzy sets for Hop count and 3 for
Maximum speed input, there exist 27 fuzzy rules(see table 6), which are elaborated in Table.

Table 6: Fuzzy Rules

1. If (Node_Power is Low) and (Hop_Count is Low) and (Max_Speed is Low) then (Trust_Route is Medium) (1) 2. If (Node_Power is Low) and (Hop_Count is Low) and (Max_Speed is Medium) then (Trust_Route is Medium) (1) 3. If (Node_Power is Low) and (Hop_Count is Low) and (Max_Speed is High) then (Trust_Route is Low) (1) 4. If (Node_Power is Low) and (Hop_Count is Medium) and (Max_Speed is Low) then (Trust_Route is Low) (1) 5. If (Node_Power is Low) and (Hop_Count is Medium) and (Max_Speed is Medium) then (Trust_Route is Low) (1) 6. If (Node_Power is Low) and (Hop_Count is Medium) and (Max_Speed is High) then (Trust_Route is V._Low) (1) 7. If (Node_Power is Low) and (Hop_Count is High) and (Max_Speed is Low) then (Trust_Route is Low) (1) 8. If (Node_Power is Low) and (Hop_Count is High) and (Max_Speed is Medium) then (Trust_Route is V._Low) (1) 9. If (Node_Power is Low) and (Hop_Count is High) and (Max_Speed is High) then (Trust_Route is V._Low) (1) 10. If (Node_Power is Medium) and (Hop_Count is Low) and (Max_Speed is Low) then (Trust_Route is High) (1)

11. If (Node_Power is Medium) and (Hop_Count is Low) and (Max_Speed is Medium) then (Trust_Route is High) (1)

12. If (Node_Power is Medium) and (Hop_Count is Low) and (Max_Speed is High) then (Trust_Route is High) (1) 13. If (Node_Power is Medium) and (Hop_Count is Low) and (Max_Speed is High) then (Trust_Route is High) (1) 14. If (Node_Power is Medium) and (Hop_Count is Low) and (Max_Speed is High) then (Trust_Route is High) (1) 15. If (Node_Power is Medium) and (Hop_Count is Medium) and (Max_Speed is Low) then (Trust_Route is Medium) (1) 16. If (Node_Power is Medium) and (Hop_Count is Medium) and (Max_Speed is Medium) then (Trust_Route is Medium) (1)

17. If (Node_Power is Medium) and (Hop_Count is Medium) and (Max_Speed is High) then (Trust_Route is Low) (1) 18. If (Node_Power is Medium) and (Hop_Count is High) and (Max_Speed is High) then (Trust_Route is Low) (1) 19. If (Node_Power is High) and (Hop_Count is Low) and (Max_Speed is Low) then (Trust_Route is V_High) (1) 20. If (Node_Power is High) and (Hop_Count is Low) and (Max_Speed is Medium) then (Trust_Route is V_High) (1) 21. If (Node_Power is High) and (Hop_Count is Low) and (Max_Speed is Low) then (Trust_Route is V_High) (1) 22. If (Node_Power is High) and (Hop_Count is Medium) and (Max_Speed is Low) then (Trust_Route is High) (1) 23. If (Node_Power is High) and (Hop_Count is Medium) and (Max_Speed is Medium) then (Trust_Route is High) (1) 24. If (Node_Power is High) and (Hop_Count is Medium) and (Max_Speed is High) then (Trust_Route is High) (1) 25. If (Node_Power is High) and (Hop_Count is High) and (Max_Speed is Low) then (Trust_Route is High) (1) 26. If (Node_Power is High) and (Hop_Count is High) and (Max_Speed is Medium) then (Trust_Route is Medium) (1) 27. If (Node_Power is High) and (Hop_Count is High) and (Max_Speed is High) then (Trust_Route is Medium) (1) 


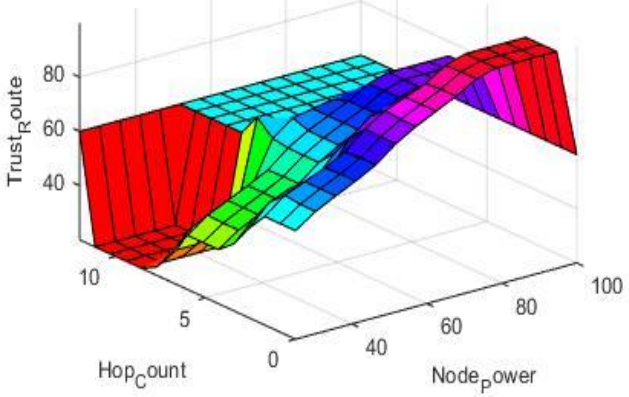

Figure 7: Trust value w.r.t. Hop count and Node power As shown in figure 7 , trust value will vary as the hop count and node power will vary from low to high and vice-versa. If hop count is low and node power is average to high, trust value having more potential.

\section{B. Network Simulator -based implementation:}

\section{Simulation environmental setup:}

For simulating the proposed algorithm AODV-F in a wireless environment, we have used NS-2.35(network simulator). NS-2[9] is a very popular and most likely network simulator that is designed based on $\mathrm{C}++$ environment. Graph designing and nam module is also available in this simulator. The simulation was carried out for 100s in a wireless network having 35 movable wireless nodes(see table 7). Performance evaluation work was done for AODV, AOMDV, AODV-F, DSR, and DSDV routing protocols at $825 \times 542$ network area. Performance parameters were considered as: end-to-end delay, overall average delay, throughput, normalized routing load, packet delivery ratio, packet delivery fraction, and pause time. Also a comparison work was carried out for AODV, DSR, DSDV, AOMDV, and AODV-F with varying pause times. The detailed parameters used for simulation work, is detailed in table.

Table 7: Simulation parameters

\begin{tabular}{|c|c|}
\hline Parameter Name & Value \\
\hline Network simulator type & NS 2.35 \\
\hline Protocols & AODV,AOMDV,DSR,DSDV,AODV-F \\
\hline Number of Nodes & 35 \\
\hline Network Area & $\mathrm{X}=825, \mathrm{y}=542$ \\
\hline Max. Simulation time & $100 \mathrm{~s}$ \\
\hline Max. Speed & $25 \mathrm{~m} / \mathrm{s}$ \\
\hline Max. packets in queue & 40 \\
\hline Topology type & Random \\
\hline Agent type & UDP \\
\hline Pause time & $15,30,45,60,75,90 \mathrm{~s}$ \\
\hline Application type & CBR \\
\hline Packet size & 530 bytes \\
\hline CBR-Packet Size & 500 bytes \\
\hline Transmission rate & 1.8 \\
\hline Intervals & 0.008 \\
\hline Bandwidth & $11 \mathrm{Mb}$ \\
\hline Data rate & $11 \mathrm{Mb}$ \\
\hline
\end{tabular}

We created several files on the basis of pause times (15, 30, $45,60,75,90$ s) by typing below command with maximum speed $25 \mathrm{~m} / \mathrm{s}$ :

setdest -V 1 -n 35 -p 15 -M 25 -t $100-x$ 825 -y 542

Using above command we generate 6 files having 6 different pause times:
35-aodv-pause-15
35-aodv-pause-30
35-aodv-pause-45
35-aodv-pause-60
35-aodv-pause-75
35-aodv-pause-pause-90

To generate maximum 30 connections file (having traffic type CBR), we typed the command as given below:

ns cbrgen.tcl -type cbr -nn 35 -seed 1.0 -mc 30 -rate 3.0>35-aodv-conn-30

\section{RESULTS AND DISCUSSION}

In this section, we have found out the performance parameters for different routing protocols (AODV, AOMDV, AODV-F, DSR, and DSDV). Also a comparison and evaluation work was carried out to verify the superiority of our proposed algorithm (AODV-F). Graphical representation was performed with the help GNU plot (including in NS-2.35 ) and MS-Excel for clearly analysing the actual results.

\begin{tabular}{|c|c|c|c|c|c|}
\hline \multirow{2}{*}{$\begin{array}{l}\text { Pause_tim } \\
\text { e }\end{array}$} & \multicolumn{5}{|c|}{ Throughput[kbps] } \\
\hline & AODV & AOMDV & DSR & DSDV & AODV-F \\
\hline 15 & 242.15 & 239.77 & $\begin{array}{l}172.3 \\
0\end{array}$ & 145 & 245.32 \\
\hline 30 & 256.31 & 249.87 & $\begin{array}{l}201.2 \\
2\end{array}$ & $\begin{array}{l}185.3 \\
2\end{array}$ & 255.65 \\
\hline 45 & 283.86 & 295.06 & $\begin{array}{l}261.3 \\
4\end{array}$ & $\begin{array}{l}215.8 \\
4\end{array}$ & 315.22 \\
\hline 60 & 212.82 & 243.32 & $\begin{array}{l}184.8 \\
6 \\
\end{array}$ & $\begin{array}{l}202.1 \\
1 \\
\end{array}$ & 250.45 \\
\hline 75 & 279.72 & 301.40 & $\begin{array}{l}253.9 \\
0\end{array}$ & $\begin{array}{l}269.8 \\
6 \\
\end{array}$ & 345.65 \\
\hline 90 & 200.57 & 205.95 & $\begin{array}{l}140.4 \\
8\end{array}$ & $\begin{array}{l}197.3 \\
8\end{array}$ & 235.57 \\
\hline
\end{tabular}

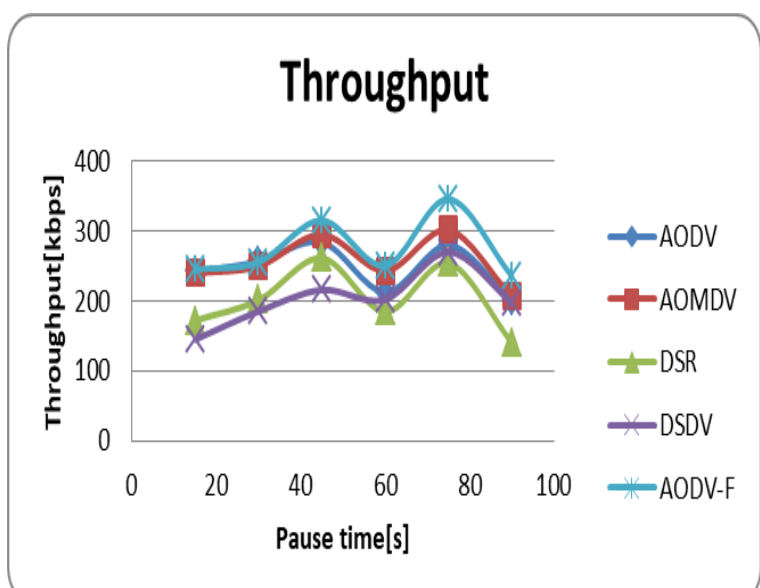

Figure 8: Pause time w.r.t. Throughput

Throughput: figure 8 and table 8 illustrate the throughput with respect to various pause times (15s-90s) for AODV, AOMDV, DSR, DSDV, and AODV-F. At pause time 75, throughput is max for AODV-F, AODV, AOMDV, and DSDV routing protocols. But it is highest for AODV-F. 
At lowest pause times, throughput for AODV-F is better as compared to traditional AODV protocol. From pause times 15 s to 90 s, AODV-F produces better results. But, DSR shows very poor results as compare to AODV, AOMDV, and AODV-F. Throughput for DSDV is less from pause times $15 \mathrm{~s}$ to 60s. When node movement is higher in the network, AODV-F performs very well (i.e. throughput is good).

Table 9: Pause time Vs Normalized Routing Load

\begin{tabular}{|c|c|c|c|c|c|}
\hline Pause time & \multicolumn{5}{|c|}{ NRL } \\
\hline & AODV & AOMDV & DSR & DSDV & AODV-F \\
\hline 15 & 2.652 & 1.480 & $\begin{array}{c}1.58 \\
5\end{array}$ & 0.194 & 1.243 \\
\hline 30 & 2.162 & 1.352 & $\begin{array}{c}1.00 \\
1\end{array}$ & 0.187 & 1.075 \\
\hline 45 & 1.686 & 0.778 & $\begin{array}{c}0.50 \\
7\end{array}$ & 0.140 & 0.582 \\
\hline 60 & 4.611 & 1.123 & $\begin{array}{c}1.17 \\
6\end{array}$ & 0.153 & 1.57 \\
\hline 75 & 2.193 & 0.690 & $\begin{array}{c}0.49 \\
8\end{array}$ & 0.105 & 0.487 \\
\hline 90 & 4.018 & 1.655 & $\begin{array}{c}1.74 \\
5\end{array}$ & 0.176 & 1.08 \\
\hline
\end{tabular}

\section{Pause time Vs NRL}

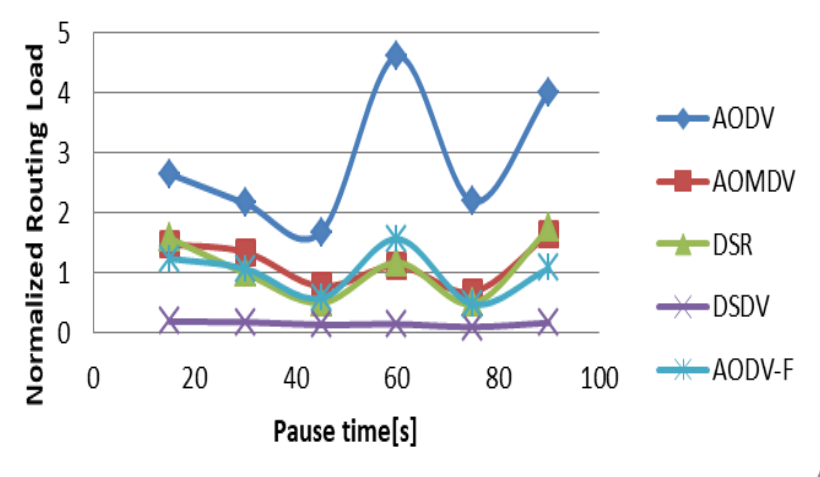

Figure 9: Pause time w.r.t. Normalized Routing Load Normalized routing load: Figure 9 , figure 15 and table 9 represent the normalized routing load with respect to various pause times. Here, NRL is evaluated for AODV, AOMDV, AODV-F, DSR, and DSDV routing protocols. For AODV, AOMDV, DSR, and AODV-F, NRL is decreasing from pause times $15 \mathrm{~s}-45 \mathrm{~s}$ and it is suddenly increased at pause times $60 \mathrm{~s}$ and 90s. But, NRL is approximately same for DSDV routing protocol at all pause-times (i.e. pause times 15s-90s). AODV-F having low NRL as compared to AODV, but it is higher than AOMDV routing protocol. DSR performs well as compared to AODV, AOMDV, and AODV-F. Overall performance for AODV-F is better than traditional AODV routing protocol.

Table 10: Pause time Vs Average E2E delay

\begin{tabular}{|c|c|c|c|}
\hline Pause Time & \multicolumn{3}{|c|}{ Average E2E Delay[ms] } \\
\hline & AODV & AOMDV & AODV-F \\
\hline 15 & 29.928 & 16.7151 & 17.65 \\
\hline 30 & 15.218 & 8.25908 & 9.52 \\
\hline 45 & $\begin{array}{c}16.315 \\
1\end{array}$ & 11.2307 & 11.17 \\
\hline 60 & $\begin{array}{c}2.9898 \\
7\end{array}$ & 11.73 & 2.32 \\
\hline 75 & $\begin{array}{c}6.3873 \\
1\end{array}$ & 7.94837 & 5.21 \\
\hline 90 & $\begin{array}{c}27.330 \\
8\end{array}$ & 20.2567 & 22.78 \\
\hline \multicolumn{4}{|c|}{} \\
\hline
\end{tabular}

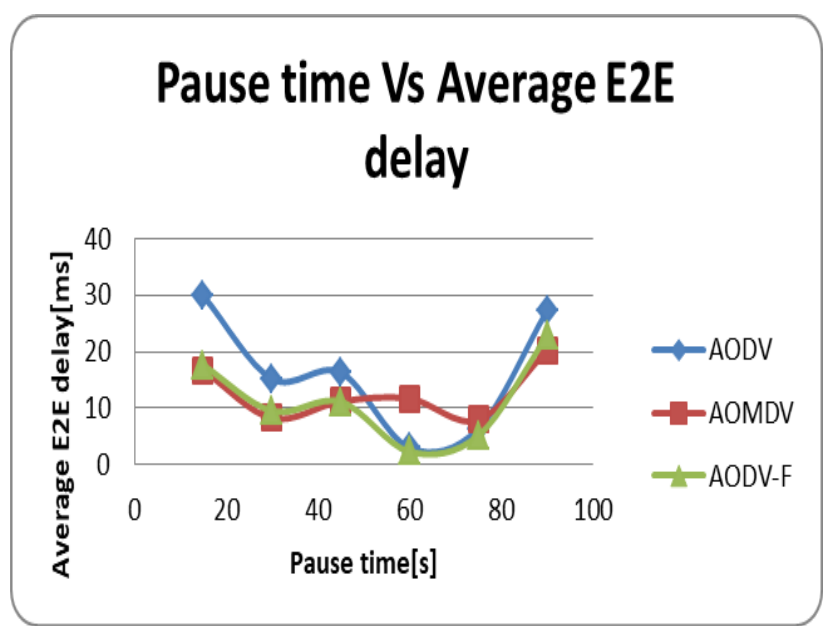

Figure 10: Pause time w.r.t. Average E2E Delay Average E2E Delay: Figure 10-11 and table 10-11 depict the average delay with respect to pause times. Average delay is varying from pause times $15 \mathrm{~s}-90$ s for all protocols. It is lowest at pause time 60s for AODV and AODV-F. But, for AOMDV, it is increasing for pause times 20s-60s and pause-times 70s-90s. Average delay is lowest at pause times 30s ,70s for AOMDV routing protocols. AODV-F performs better results as compared to AODV and AOMDV for all pause times. At highest movement of the nodes, average delay is higher for AODV routing protocol. But, it is better for AODV-F.

Table 11: Pause time Vs E2E delay

\begin{tabular}{|c|c|c|c|c|c|}
\hline Pause time & \multicolumn{5}{|c|}{ E2E Delay } \\
\hline & AODV & AOMDV & DSR & DSDV & AODV-F \\
\hline 15 & .146 & .244 & 2.47 & .0234 & .045 \\
\hline 30 & .271 & .332 & $\begin{array}{c}1.85 \\
5\end{array}$ & .0507 & .012 \\
\hline 45 & .108 & .032 & $\begin{array}{c}1.05 \\
0\end{array}$ & .0317 & .018 \\
\hline 60 & .3290 & .625 & $\begin{array}{c}2.13 \\
9\end{array}$ & .0465 & .023 \\
\hline 75 & .095 & .041 & $\begin{array}{c}1.18 \\
0\end{array}$ & .0152 & .008 \\
\hline 90 & .242 & 1.269 & $\begin{array}{c}2.38 \\
0\end{array}$ & .2857 & .175 \\
\hline
\end{tabular}

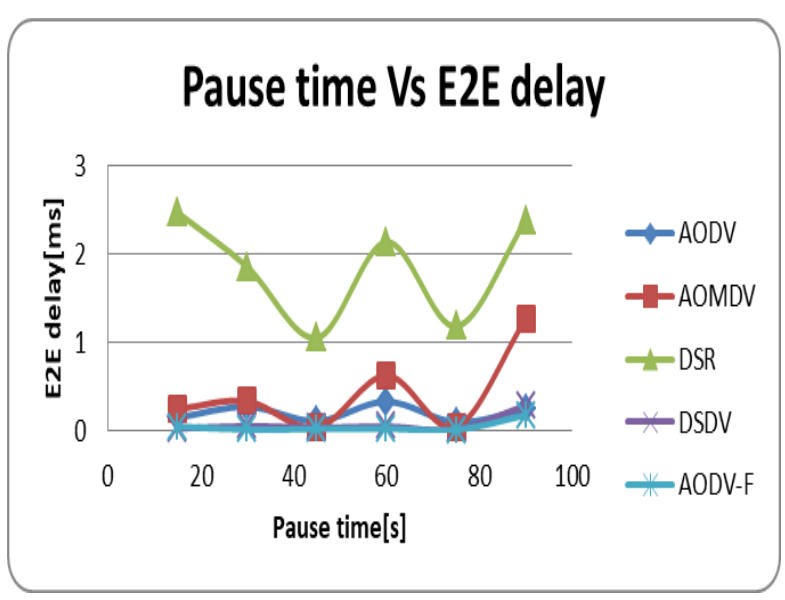

Figure 11: Pause time w.r.t. E2E Delay 
Table 12: Pause time Vs Packet delivery ratio

\begin{tabular}{|c|c|c|c|c|c|}
\hline Pause time & \multicolumn{5}{|c|}{ PDR } \\
\hline & AODV & AOMDV & DSR & DSDV & AODV-F \\
\hline 15 & .7399 & .7327 & $\begin{array}{c}.548 \\
5\end{array}$ & .4471 & .7400 \\
\hline 30 & .7818 & .7606 & $\begin{array}{c}.642 \\
2\end{array}$ & .5689 & .7900 \\
\hline 45 & .8681 & .8976 & $\begin{array}{c}.832 \\
2\end{array}$ & .6634 & .8908 \\
\hline 60 & .6495 & .7432 & $\begin{array}{c}.588 \\
2\end{array}$ & .6173 & .7200 \\
\hline 75 & .8580 & .9199 & $\begin{array}{c}.807 \\
5\end{array}$ & .8227 & .8980 \\
\hline 90 & .6149 & .6302 & $\begin{array}{c}.443 \\
2\end{array}$ & .6035 & .6405 \\
& & & & &
\end{tabular}

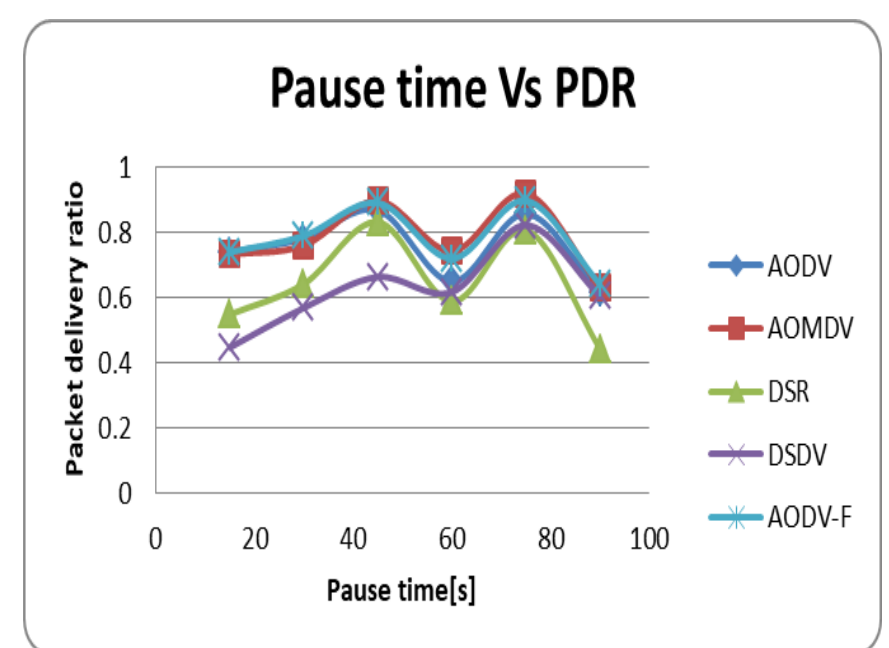

Figure 12: Pause time w.r.t. Packet Delivery Ratio Packet Delivery Ratio (PDR): Packet delivery ratio with respect to pause times is illustrated in table 12 and figure 12.figure 16 PDR for AOMDV is better than AODV from pause times 15s-90s.DSR performs poor as compared to AODV, AOMDV, and AODV-F. Due to multi-route packet delivery, AOMDV performs better than AODV routing protocol. Packet delivery ratio for AOMDV and AODV-F is approximately same. But, it is better for AODV-F than AODV. AODV-F produces better results for pause times 15s, $30 \mathrm{~s}$, and 90s. In this scenario, at higher movement of nodes, AODV-F performs superior than other protocols in respect of PDR. Packet delivery ratio is increasing from pause times 15s-50s for AODV, AOMDV, AODV-F, DSR, and DSDV routing protocols.

Table 13: Pause time Vs Packet delivery fraction

\begin{tabular}{|c|c|c|c|c|c|}
\hline Pause time & \multicolumn{5}{|c|}{ PDF } \\
\hline & AODV & AOMDV & DSR & DSDV & AODV-F \\
\hline 15 & 8197 & 7490 & $\begin{array}{c}1576 \\
2\end{array}$ & 2579 & 7285 \\
\hline 30 & 8238 & 7551 & $\begin{array}{c}1517 \\
3\end{array}$ & 3002 & 7501 \\
\hline 45 & 7457 & 5708 & $\begin{array}{c}1052 \\
7\end{array}$ & 3055 & 5255 \\
\hline 60 & 9288 & 8212 & $\begin{array}{c}1620 \\
6\end{array}$ & 4706 & 7890 \\
\hline 75 & 7515 & 5997 & $\begin{array}{c}1209 \\
2\end{array}$ & 4001 & 5608 \\
\hline 90 & 12682 & 12032 & 2105 & 6921 & 11875 \\
& & & 5 & & \\
\hline
\end{tabular}
DSDV is also lowest.
Packet Delivery Fraction: packet delivery fraction is illustrated in figure 13, figure 14 and table 13 . It is varying from pause times 15 s to 90 s. PDF is highest for DSR while it is lowest for DSDV routing protocol. AOMDV protocol performs better than DSR and AODV routing protocols. AODV-F having better results than DSR, AODV; but it is poor than AOMDV. PDF is highest at pause times 90s for all protocols. As movement of nodes is lowest, the PDF for

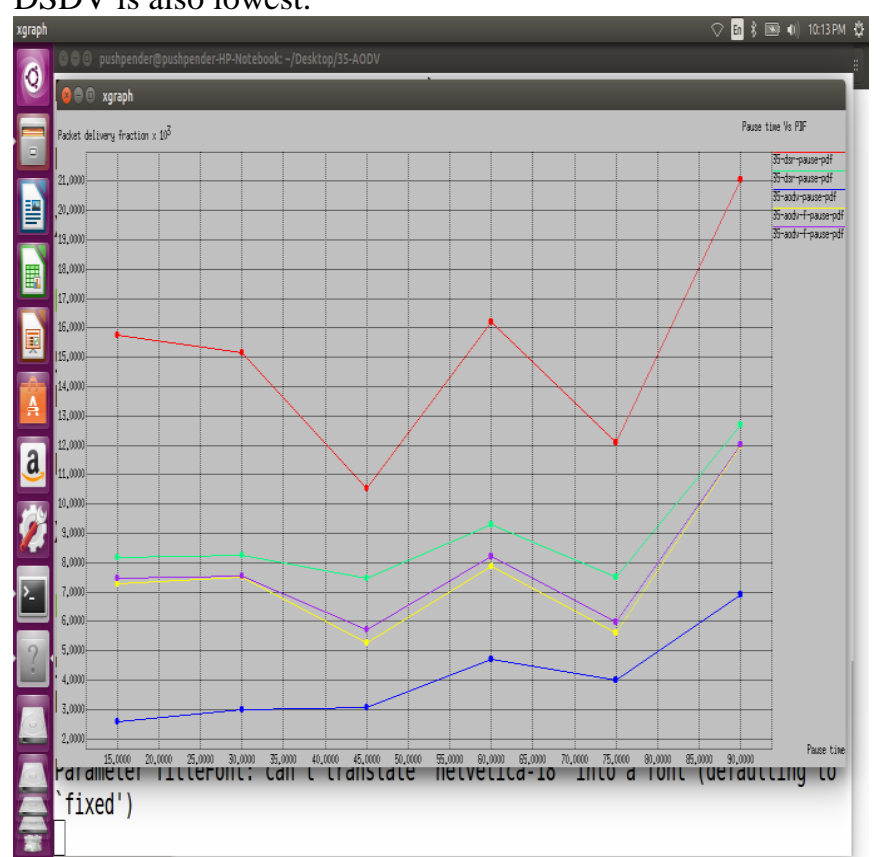

Figure 14: Pause time Vs PDF 


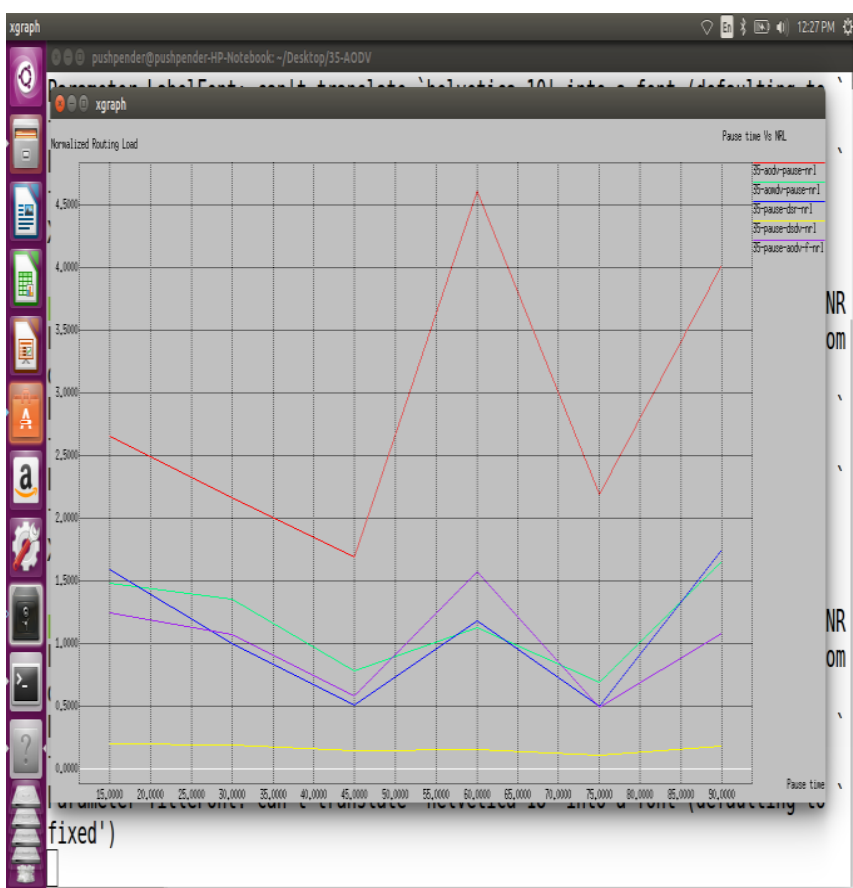

Figure 15: Pause time Vs NRL

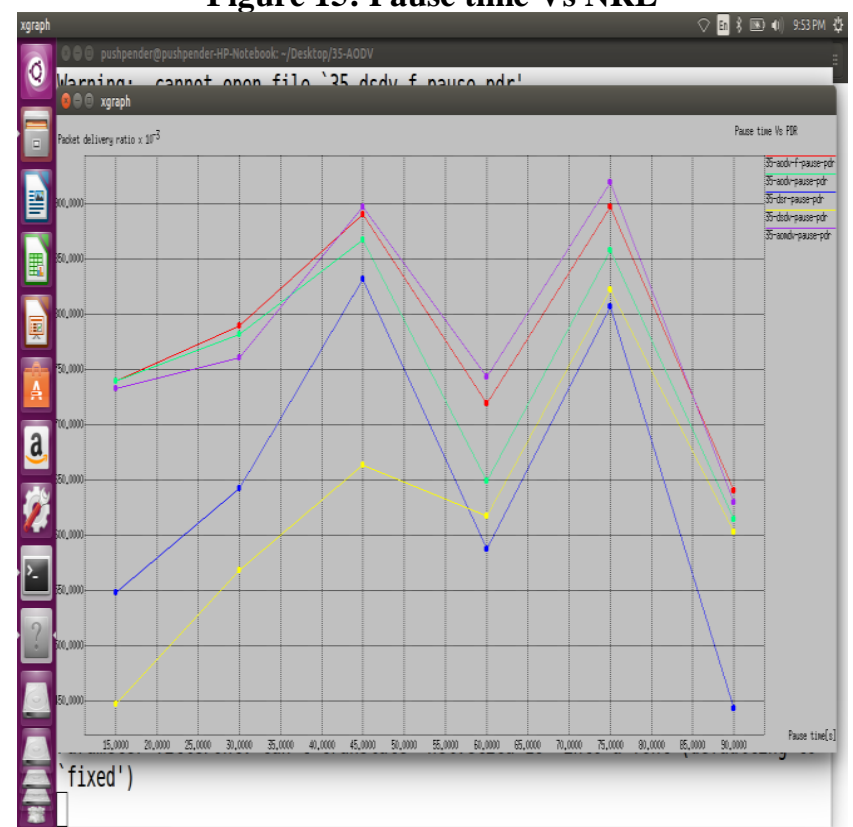

Figure 16: Pause time Vs Packet Delivery Ratio

Table 14: Pause time Vs Overall average delay

\begin{tabular}{|c|c|c|c|c|c|}
\hline Pause time & \multicolumn{5}{|c|}{ Overall average delay[ms] } \\
\hline & AODV & AOMDV & DSR & DSDV & AODV-F \\
\hline 15 & 99710 & 99591.9 & 99680. & 99861. & 99610 \\
& & & 3 & 2 & \\
\hline 30 & 99690. & 99339.6 & 99461. & 99539. & 99540 \\
& 4 & & 2 & 7 & \\
\hline 45 & 99438. & 99002.5 & 99375. & 99894. & 99327 \\
& 6 & & 3 & 1 & \\
\hline 60 & 99709. & 99446 & 99667. & 99844. & 99650.8 \\
& 5 & & 3 & 4 & \\
\hline 75 & 99697 & 99699.1 & 99653. & 99825. & 99600 \\
& & & 8 & 3 & \\
\hline 90 & 99675. & 99702.5 & 99678. & 99322 & 99590.8 \\
& 3 & & 1 & & \\
\hline
\end{tabular}

\section{Pause time Vs overall delay}

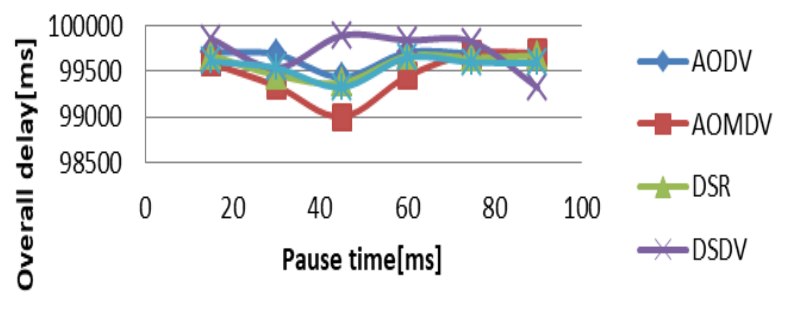

Figure 17: Pause time Vs Overall Delay

Overall average delay: Overall average delay with respect to pause times is depicted in figure 17 and table 14. It is lowest for AOMDV while it is highest for DSDV routing protocol. Overall average delay for AOMDV is lowest at pause time 40s. it is varying for all protocols in this scenario from pause times 15s-90s. AODV-F performs better than AODV, DSR, and DSDV routing protocols. It is decreasing for AODV-F from pause times 60s-90s. In this scenario, as pause time is varying, overall average delay is also varying for all the routing protocols.

\section{CONCLUSION}

To reduce the packet loss delay, improve the throughput, and enhance the end-to-end data delivery in a successful manner, we have proposed enhanced on demand routing algorithm. This will consider speed and battery power as the parameters to calculate the route trust values. The proposed algorithm AODV-F produces the better results in respect of throughput, end-to-end delay, normalized routing load and packet delivery ratio. In some cases, AOMDV is better as compare to AODV, AODV-F, DSR and DSDV routing protocols. AODV-F also shows better results on low pause times in respect of throughput and overall delay. DSR produces poor results when performance metrics like normalized routing load, end-to-end delay and packet delivery fraction are considered. Overall AODV-F presents better results on low to high pause times. In future, we will consider more parameters to calculate the route trust values.

\section{REFERENCES}

1. Mohammad Samadi Gharajeh, and Sohrab Khanmohammadi , "Static Three-Dimensional Fuzzy Routing Based on the Receiving Probability in Wireless Sensor Networks", Computers, volume 2, 2013, pp 152-175.

2. Essam Natsheh, Adznan Jantan, Sabira Khatun, and Shamala Subramaniam, "Adaptive Optimizing of Hello Messages in Wireless Ad-Hoc Networks", The International Arab Journal of Information Technology, Vol. 4, No. 3, July 2007, pp. 191-200.

3. Antonio M. Ortiz, Fernando Royo,Teresa Olivares, Jose C. Castillo Luis Orozco-Barbosa,Pedro J. Marron, "Fuzzy-logic based routing for dense wireless sensor networks", Telecommun Syst, Springer,September, 2011, pp. 1-12.( DOI 10.1007/s11235-011-9597-y)

4. Mukesh kumar Garg, Neeta Singh, Poonam Verma, "Fuzzy rule-base approach for design and analysis of a Trust-based secure Routing Protocol for MANETs", International Conference on Computational Intelligence and Data Science (ICCIDS 2018), Precedia Computer Science 132(2018) 653-658. ELESEVIER.

5. Xing Hu, Linhua Ma, Yongqiang Ding, Jin Xu, Yan Li, and Shiping Ma, "Fuzzy Logic-Based Geographic Routing Protocol for Dynamic Wireless Sensor Networks", Sensors, 2019, 19, 196; doi 10.3390/s19010196 pp. 1-21, January, 2019.
Published By:

Blue Eyes Intelligence Engineering \& Sciences Publication 
6. Gholamreza Kakamanshadi, Savita Gupta and Sukhwinder Singh, "FUZZY INFORMER HOMED ROUTING PROTOCOL FOR WIRELESS SENSOR NETWORK", International Journal of Computer Networks \& Communications (IJCNC) Vol.11, No.4, July 2019, pp. 43-60 DOI: 10.5121/ijcnc.2019.11403

7. Sangeetha Pushpan and Bhanumathi Velusamy, "Fuzzy-Based Dynamic Time Slot Allocation for Wireless Body Area Networks", Sensors 2019, 19, 2112, pp. 1-20; doi:10.3390/s19092112

8. https://www.mathworks.com

9. https://www.isi.edu/nsnam/ns/

10. Pushpender Sarao, "Ad Hoc On-demand Multipath Distance Vector Based Routing in Ad-Hoc Networks", Journal of Communications Vol. 14, No. 8, August 2019, pp. 706-714.

11. Pushpender Sarao, "A Throughput Based Fuzzy System In MANET", International Journal of Recent Technology and Engineering (IJRTE) ISSN: 2277-3878, Volume-8 Issue-2, July 2019, pp. 2221-2228.

\section{AUTHOR'S PROFILE}

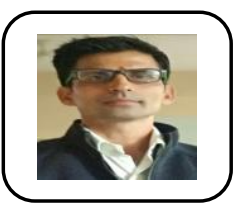

Dr. Pushpender Sarao is a Professor in CSE department. He is $\mathrm{BE}$ (honors), M.Tech, $\mathrm{PhD}$ in Computer Science and Engineering. He has worked as HOD and Dean Academics in Somany Institute of Technology \& Management, Rewari (2011-2016). In 2013, he was awrded with "Best Teacher Award-2013" by Somany Educational Society. He is author of five books in computer science, wireless networks. He is a member of IEEE, ACM, ICSES, RES, and IAENG, and life member of CSI, ISTE and IEI. He got published more than 58 research papers in national and international reputed journals. Also he shared his research experience in more than 22 national and international conferences. He attended several FDP and seminars/workshops in engineering institutions and state universities. He is member of editorial board for 19 national and international journals. His main research work focuses on routing protocols in wireless mesh networks, mobile ad-hoc network. He has 8.5 years of teaching experience and 10 years of Industrial Experience. 